\title{
An experimental investigation of heat transfer of free convection on triangular fins in order to optimize the arrangement of fins
}

\author{
Hamid Reza Goshayeshi, Reza Vafa Toroghi \\ Department of Mechanical Engineering, Mashhad Branch, Islamic Azad University, Mashhad, Iran
}

Email address:

Goshayshi@yahoo.com (H. R. Goshayeshi)

\section{To cite this article:}

Hamid Reza Goshayeshi, Reza Vafa Toroghi. An Experimental Investigation of Heat Transfer of Free Convection on Triangular Fins in Order to Optimize the Arrangement of Fins. International Journal of Science, Technology and Society. Vol. 2, No. 5, 2014, pp. 152-160. doi: $10.11648 /$ j.jijsts.20140205.18

\begin{abstract}
In this study, the effect of free convection heat transfer on a vertical surface on which the triangular fins are vertically placed has been investigated numerically and experimentally. In order to numerically solve the system of governing equations, the finite volume method has been used, and the analysis has been conducted by FLUENT software. Free convection heat transfer in four groups of built fins has been tested using the available testing tool. Results show that increasing the fins increases the coefficient of heat transfer of free convection. In addition, increasing the distance decreases the heat transfer at first until the optimum distance is achieved, and then increasing the distance increases the amount of heat transfer.
\end{abstract}

Keywords: Free Convection, Triangular Fins, Vertical Surface, Heat Sink

\section{Introduction}

The study of convective heat transfer originates from human's desire to understand and predict the amount of energy which is observed through any fluid flow as an energy transferor. The science of convection is an interdisciplinary field which connects two earlier sciences, Heat Transfer and Fluid Mechanics. Therefore, investigation of any issues regarding convection must be based on a comprehensive understanding of heat transfer and fluid mechanics principles. In terms of forces applied to a fluid, there are two kinds of convection: free convection and forced convection. In forced convection, fluid flow is caused by an external force. For instance, we can refer to movement of a fluid which is induced by a fan or pump, or movement of a solid object throughout a fluid; in these mechanisms, we deal with forced convection, while free convection is observed as a result of fluid movement induced by density changes which are caused by heat transfer process. In other words, fluid movement in free convection is caused by a buoyant force applied to the fluid when its density decreases approximate to the surface as a result of heat loss. Of course, if the fluid is not influenced by an external force such as gravity, there will be no buoyant force. However, gravity is not the only force which can create free convection. For example, a fluid which is trapped into a circulating machine and is influenced by eccentricity force field can create free convection flow, if one or more surfaces are heated in contact with the fluid. In general, since the pace of fluid flow in free convection is less than forced convection, the convection heat transfer rate is also less. This fact may make us consider less importance for free convection process, but it is not actually true. In most of the systems which encompass different mechanisms of heat transfer, free convection creates high resistance against heat transfer. Therefore, it plays an important role in designing and determining the characteristics of a system. Also, when we are dealing with heat transfer rate reduction or outcome cost reduction, free convection is preferable to forced convection.

Now, it is better to use a set of fins (called heat sink) instead of a single one in order to achieve more efficiency and yield.

Numerous researches are conducted regarding fins and heat sinks. Brodowicz [1] investigated flow and temperature fields on a hot vertical surface. He found that 
unlike initial edge, the fields do not circumfuse to the long distances, although he had isolated the initial edge. Moreover, he concluded that the flow is not persistent on the surface edge and brim of boundary layer. Numerically solving of governing equations on boundary layer is performed by Hellums and S.W. Churchill [2] for vertical surfaces and stepwise changes of surface temperature are achieved. The results tend to steady state in terms of large times and show a minimum value for Nusselt number. Most of the works in this context hold true for low-Prandtl numbers and calculation errors in high Prandtl numbers are not negligible. Zeghmati [3] studied free convection on horizontal surface, theoretically and experimentally. In his experimental study, Zeghmati used temperature distribution in different places by a system which allowed him to measure the temperature and the corresponding place on the surface; then, he obtained the value of Nusslet number and coefficient of heat transfer.

Comunelo and Güths [4] investigated free convection flow on vertical surfaces with stable temperature, numerically and experimentally. They examined coefficient of convection heat transfer on a surface made of copper by five heat flux meters.

Yüncü and Anbar [5] conducted their experimental research on function of rectangular fin on a horizontal-base surface in free convection. In this research, they calibrated the system and then obtained net heat transfer and coefficient of free convection heat transfer. Saikhedkar and Sukhatme [6] observed that increasing of Grashof number resulted in increasing of convection heat transfer and decreasing of radiation heat transfer. Guglielmini [7] and et al. carried out some experiments on zigzag and vertical fins and showed that the function heat transfer in vertical and zigzag fins is better than vertical and U-shaped fins. Rao and Venkateshan [8] carried out some experiments on horizontal fins. The showed that larger heat currents are observed in short fins rather than long ones. Moreover, convection heat transfer relative to the spaces between fins increases linearly.

Rio [9] examined free and radiation convection heat transfer of vertical fins in contact with open environment by means of consolidated analysis. In this research, geometrical parameters of fins such as length and space between fins and also heat parameters such as temperature of fins and emission coefficient of them were investigated. Naseriyan [10] and Fahiminiya [11] conducted an experimental research on free convection heat transfer on flat and V-shaped fins and concluded that heat transfer rate increases with spaces between fins in terms of same height and length until it reaches to a maximum point. Mokheimer [12] investigated the influence of temperature on coefficient of free convection and outcome of circular, rectangular and triangular fins and parabolic concave and parabolic convex profiles by finite difference method. Also, he compared the values of heat transfer coefficient with Gardner [13], Ullman and Kalman [14]. [15] $\mathrm{He}$ experimentally studied free convection heat transfer on triangular fins which were located vertically and horizontally, and compared these two situations. Bert [16] investigated the heat transform in triangular fins in stable temperature using difference method. Moitsheki [17] studied heat transfer in longitudinal fins which were triangular and parabolic. He used certain boundary conditions in order to investigate parameters of fin shape, outcome and distribution of temperature on fin surface. [18] examined heat sink cooling with triangular fins. The results showed that fin cooling depends on Reynolds number and height of fin. Sun and et al [19]. studied the numerical analysis of convection for triangular fins in closed environment. Their reports included the impact of heat transfer and temperature and current distribution on triangular fin. Worachest and et al [20]. examined the efficiency of triangular, parabolic concave, parabolic convex and rectangular fins. They suggested two methods for each profile to achieve fin efficiency in certain boundary conditions. Their results showed that fins with larger cross sections have higher heat transfer and more efficiency.

\section{Governing Equations}

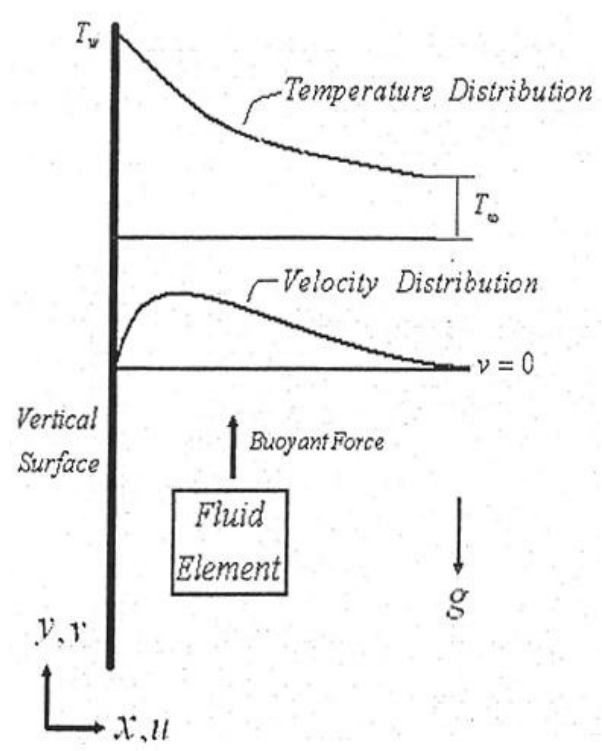

Figure 1. Geometry and Coordinate System.

In order to perform an analysis, we should obtain the differential equation of this layer movement. To do so, we draw $\mathrm{y}$ axis horizontally and $\mathrm{x}$ axis vertically as shown in Figure. 1. The 2-D is considered with physical characteristics and stable wall temperature (more than temperature of free input flow). Therefore, an upward flow is produced by a buoyant forced. Two ends of the surface are in contact with an environment with free convection temperature. The impact of compressibility in free convection with low speed can be neglected and we can only consider the slow flow regime [21]. Governing equations of conservation of mass, momentum and energy for constant and slow flow are expressed as: 


$$
\frac{\partial \mathrm{u}}{\partial \mathrm{x}}+\frac{\partial \mathrm{v}}{\partial y}=0
$$

The momentum equation in $\mathrm{x}$-direction will be as equation (2):

$$
\rho\left(u \frac{\partial u}{\partial x}+v \frac{\partial u}{\partial y}\right)=-\frac{\partial p}{\partial x}+\frac{\partial}{\partial x}\left(\mu \frac{\partial u}{\partial x}\right)+\frac{\partial}{\partial y}\left(\mu \frac{\partial u}{\partial y}\right)
$$

Simplifying the momentum equation in y-direction, we obtain equation (3).

$$
\rho\left(u \frac{\partial v}{\partial x}+v \frac{\partial v}{\partial y}\right)=-\frac{\partial p}{\partial y}+\frac{\partial}{\partial x}\left(\mu \frac{\partial v}{\partial x}\right)+\frac{\partial}{\partial y}\left(\mu \frac{\partial v}{\partial y}\right)-\rho g
$$

The energy equation will be as follow:

$$
\left(u \frac{\partial\left(\rho C_{p} T\right)}{\partial x}+\mathrm{V} \frac{\partial\left(\rho C_{p} T\right)}{\partial y}\right)=\frac{\partial}{\partial x}\left(k \frac{\partial T}{\partial x}\right)+\frac{\partial}{\partial y}\left(k \frac{\partial T}{\partial y}\right)
$$

The boundary conditions will be as follow:

$$
\left\{\mathrm{x}=0, \mathrm{u}=\mathrm{v}=0, \mathrm{~T}=\mathrm{T}_{\mathrm{w}} \mathrm{v}=0, \mathrm{~T}=T_{\infty}, \mathrm{x} \rightarrow \infty\right\}
$$

Assuming that there is no parameter change in $\mathrm{x}$ direction, equation (2) will be deleted. Also, the pressure gradient alongside the y axis is induced by changes in fluid height. The speed of $\mathrm{u}, \mathrm{v}$ and their derivations outside of boundary condition is zero.

$$
\frac{\partial p}{\partial y}=-\rho \infty \mathrm{g}
$$

Placing equation (3) in equation (6) we will have:

$$
\mathrm{p}\left(\mathrm{u} \frac{\partial \mathrm{v}}{\partial \mathrm{x}}+\mathrm{v} \frac{\partial \mathrm{v}}{\partial \mathrm{x}}\right)=\mathrm{g}(\rho \infty-\rho)+\mu \frac{\partial^{2} \mathrm{v}}{\partial \mathrm{y}^{2}} \frac{\partial \mathrm{p}}{\partial \mathrm{y}}
$$

We can explain density differentiate based on volumetric expansion coefficient.

$$
\begin{gathered}
\beta .=-\frac{1}{\rho} \cdot\left(\frac{\partial \rho}{\partial \mathrm{T}}\right) \mathrm{P} . . \beta \approx-\frac{1}{\rho} \frac{\rho_{\infty}-\rho}{\mathrm{T}_{\infty-\mathrm{T}}} \\
\mathrm{u} \frac{\partial \mathrm{v}}{\partial \mathrm{x}}+v \frac{\partial \mathrm{v}}{\partial y}=g \beta\left(\mathrm{T}_{\infty}-\mathrm{T}\right)+\vartheta \frac{\partial^{2} \mathrm{v}}{\partial \mathrm{y}^{2}}
\end{gathered}
$$

The equation of momentum in boundary layer shows the speed of free convection which is caused by temperature gradient. Therefore, the equation of momentum (8) and equation of energy (4) must be solved simultaneously, because speed and temperature are passive. Now, we must guess temperature and speed distributions based on boundary conditions and consider them in the equations.

A finite volume method is used in order to numerically solve the governing transient equation system. Moreover, simple algorithm [22] is used for the relationship between pressure and speed. Discretization of the terms convection and penetration is performed by power project and central differentiation, respectively.

\section{Experiment Device}

Acute information about a physical process is often achieved through practical measurements. Although there are many advancements in numerical simulations and computer modeling of heat transfer, confirmation of them by experimental results is essential, because all characteristics and features of heat transfer have not yet been discovered and they are manifested in experimental measurements. Moreover, in order to simplify the governing equations of free convection heat transfer, we need to achieve a better understanding of the related phenomena. These two main reasons together with complexity of free convection heat transfer process have caused unreliability of numerical techniques and modeling of the procedure; therefore, we need experimental results to confirm the founding derived from them. Now, we investigate free convection heat transfer by means of the available device. Figures 2 and 3 show the abovementioned device.

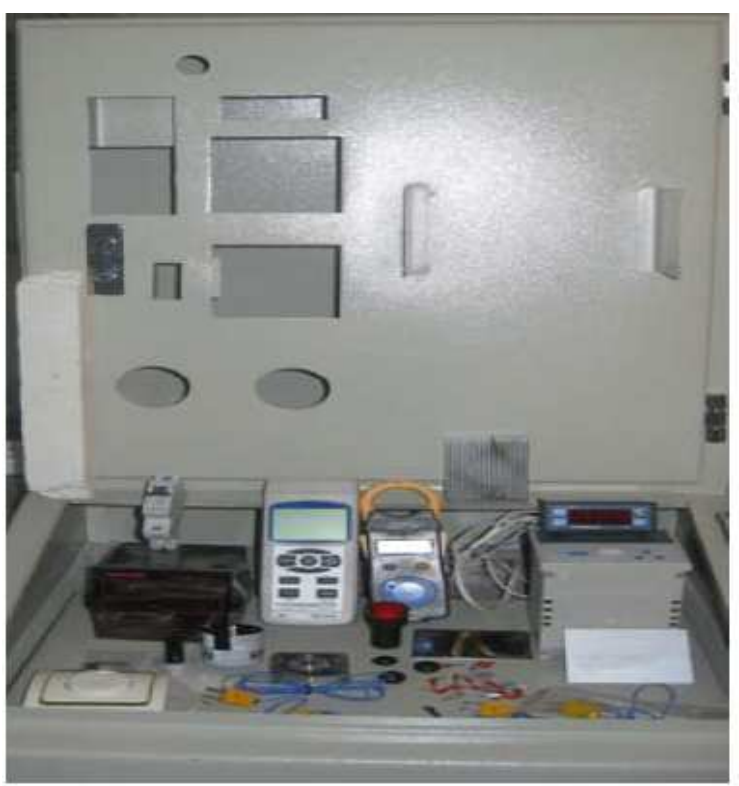

Figure 2. Components of the device.

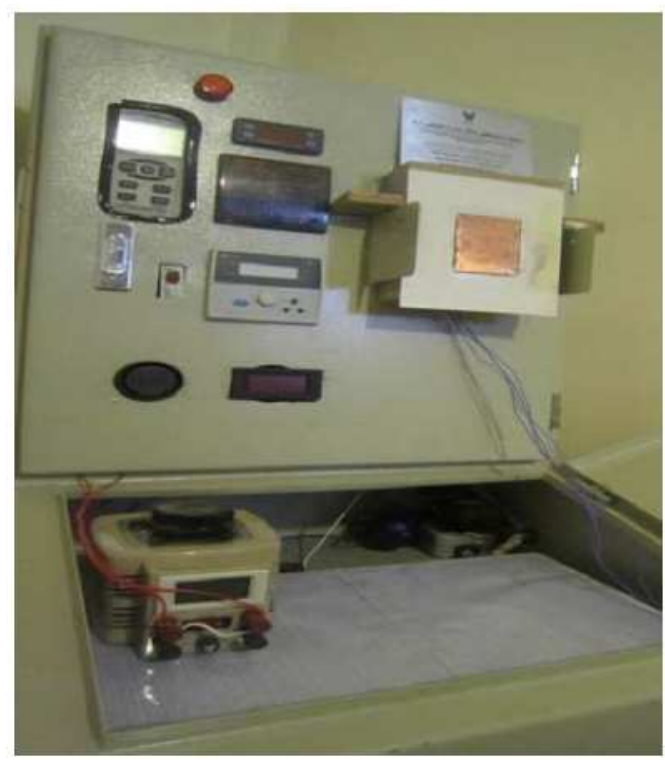

Figure 3. A view of the device 


\section{Experimental Solution}

In this study, we investigate four kinds of triangular fins arrangement and examine their locations in order to analyze characteristics of flow and heat transfer, experimentally. The dimensions of triangular fins are listed in Table 1.

Table 1. Dimensions of fin configuration.

\begin{tabular}{llll}
\hline $\begin{array}{l}\text { Fin length } \\
\text { L(mm) }\end{array}$ & $\begin{array}{l}\text { Fin width } \\
\mathbf{W}(\mathbf{m m})\end{array}$ & $\begin{array}{l}\text { Fin thickness } \\
\mathbf{t}(\mathbf{m m})\end{array}$ & $\begin{array}{l}\text { Base } \\
\text { thickness } \\
\mathbf{d}(\mathbf{m m})\end{array}$ \\
\hline 80 & 59.8 & 1 & 1.4 \\
Fin height & Fin space & Number of fins & \\
$\mathrm{h}(\mathrm{mm})$ & S(mm) & $\mathrm{n}$ & \\
20 & 3.9 & 4 & \\
20 & 8.8 & 7 & \\
20 & 7.4 & 8 & \\
20 & 18.6 & 13 & \\
\hline
\end{tabular}

The created geometry is shown in Figure 4.

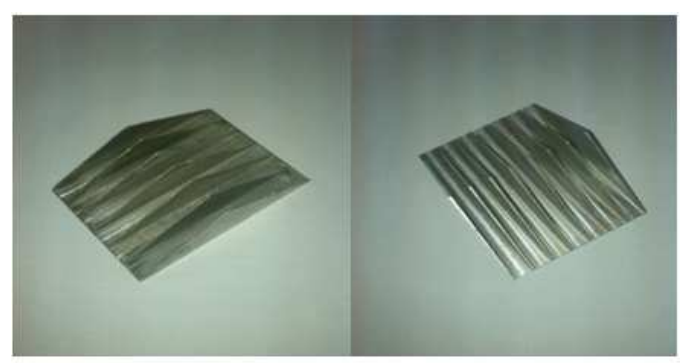

(a)7 Fins

(b) 8 Fins

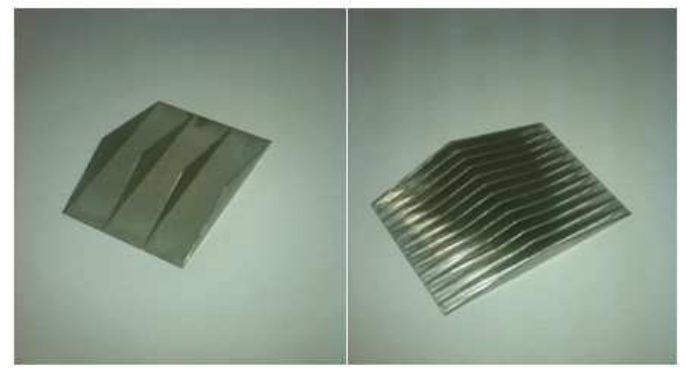

(b) 4 Fins

(c) 13 Fins

Figure 4. Variation of Fins.

\section{Results and Discussions}

In this research, some experiments are performed on four series of fins (Figure 4) in three different temperatures by the available device. FLUENT software is used to confirm the results.

Temperature differences between base surface and environment are considered 100,45 and $72{ }^{\circ} \mathrm{C}$. The results of all three states are investigated and compared with experimental results.

The investigations shown in Figures 5 and 6 which are obtained in two different temperatures show that heat transfer rate increases as the space between fins increases in the same height and length, until it reaches to a maximum point. Then, the heat transfer rate decreases as the space between fins increases. The maximum point is optimum distance $(7 / 9 \mathrm{~mm})$.

If the space between fins decreases, heat transfer will increase, but keep in mind that the surface length should not be considered too high, because turbulence may be observed. Optimum distance is a value in which there is no interference of boundary layer on surfaces. When the space between fins is small or the number of fins is large, a boundary layer is produced on the surface after air entry and it makes interference. But, in optimum distance, thickness of boundary layer is less than space between fins and the boundary level expands without interference. As shown in the diagram, we can easily understand that in less temperature difference, heat sink needs less power to reach considered temperature.

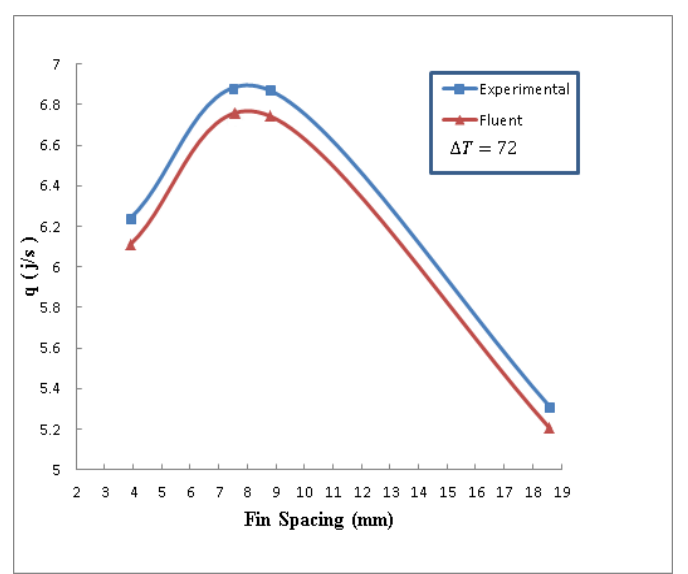

Figure 5. Changes of free convection heat transfer rate due to changes of space between fins with temperature difference of $72^{\circ} \mathrm{C}$.

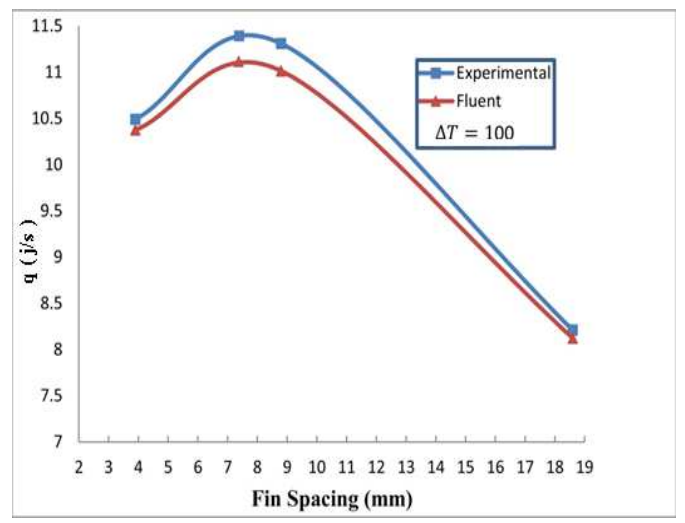

Figure 6. Changes of free convection heat transfer rate due to changes of space between fins with temperature difference of $100^{\circ} \mathrm{C}$.

Figures 7, 8 and 9 show temperature changes on heat sink. The temperature underneath the fin is higher than its tip and the heat is transferring from underneath to the top.

If the space between fins decreases, heat transfer will increase, but keep in mind that the surface length should not be considered too high, because turbulence may be observed. Optimum distance is a value in which there is no interference of boundary layer on surfaces. When the space between fins is small or the number of fins is large, a boundary layer is produced on the surface after air entry and it makes interference. But, in optimum distance, 
thickness of boundary layer is less than space between fins and the boundary level expands without interference. As shown in the diagram, we can easily understand that in less temperature difference, heat sink needs less power to reach considered temperature.

Figures 7, 8 and 9 show temperature changes on heat sink. The temperature underneath the fin is higher than its tip and the heat is transferring from underneath to the top.

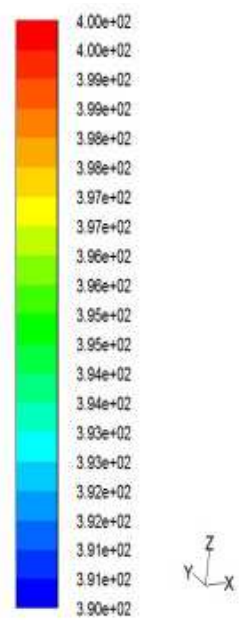

Contours of Static Temperature $(k)$

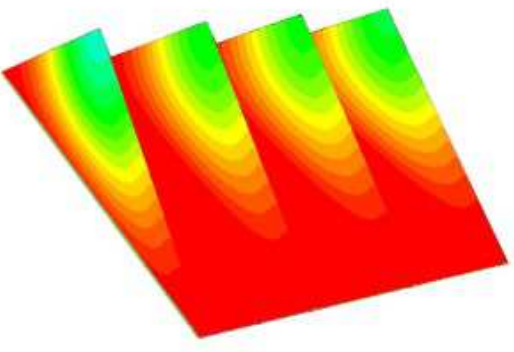

z

ENT 6.3 (3d, pbns, lam)

Figure 7. Contour changes of 4-fin heat sink temperature.
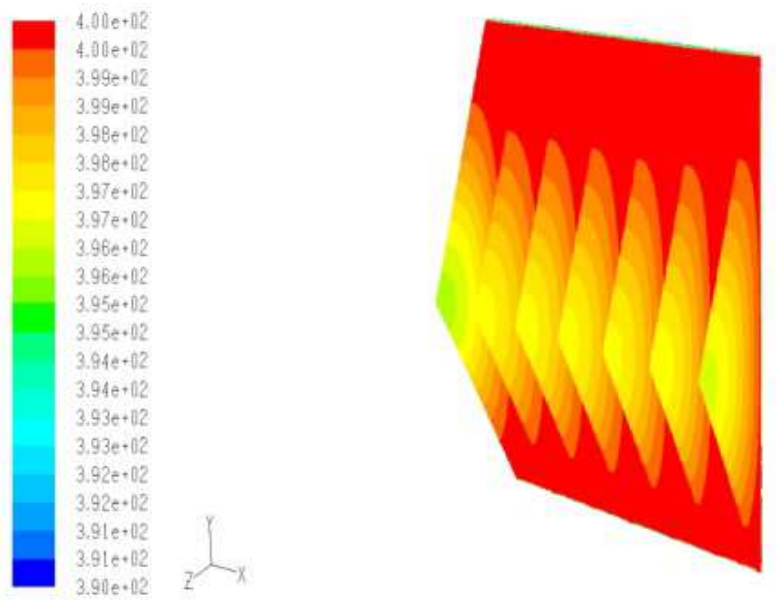

Contours of Static Temperature (k)

Figure 8. Contour changes of 7-fin heat sink temperature. 

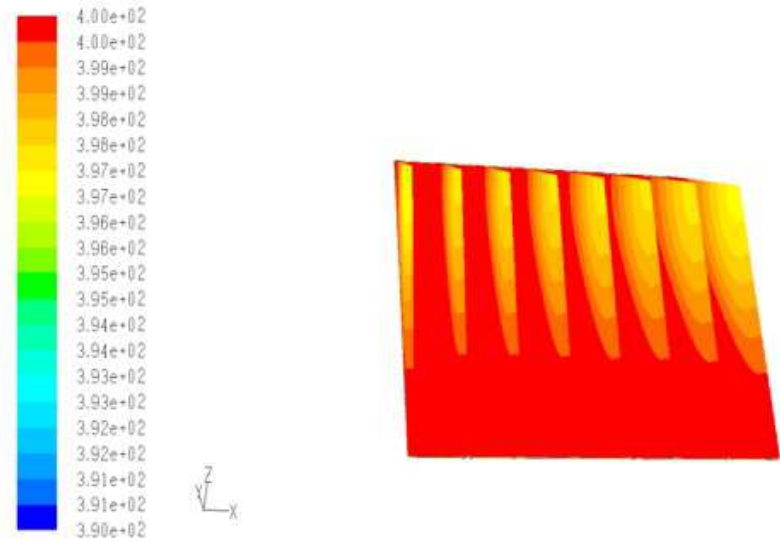

Contours of Static Temperature $(k)$

FLUENT 6.3 (3d, pbns, lam)

Figure 9. Contour changes of 8-fin heat sink temperature.

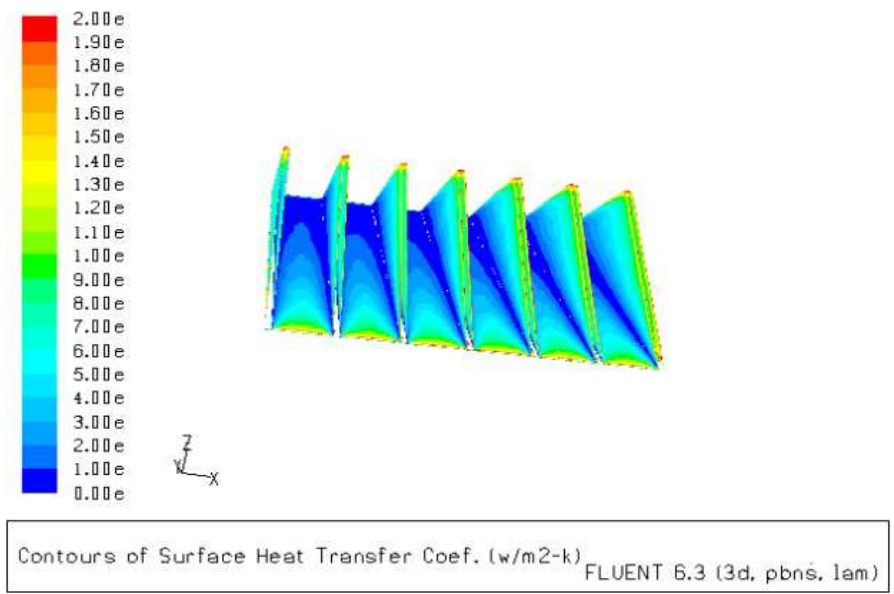

Figure 10. Contour of free convection heat transfer coefficient for 7-fin heat sink.
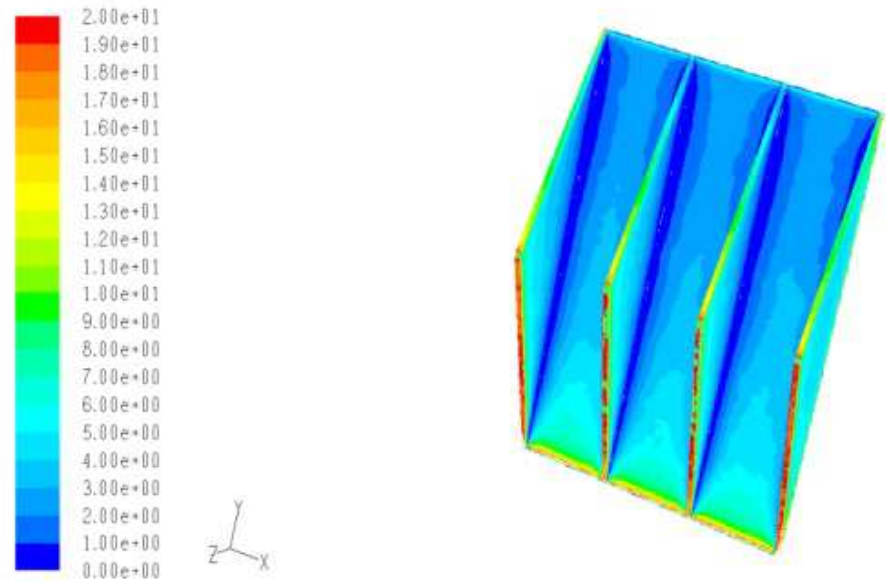

Contours of Surface Heat Transfer Coef. (w/m2-k)

Figure 11. Contour of free convection heat transfer coefficient for 4-fin heat sink. 


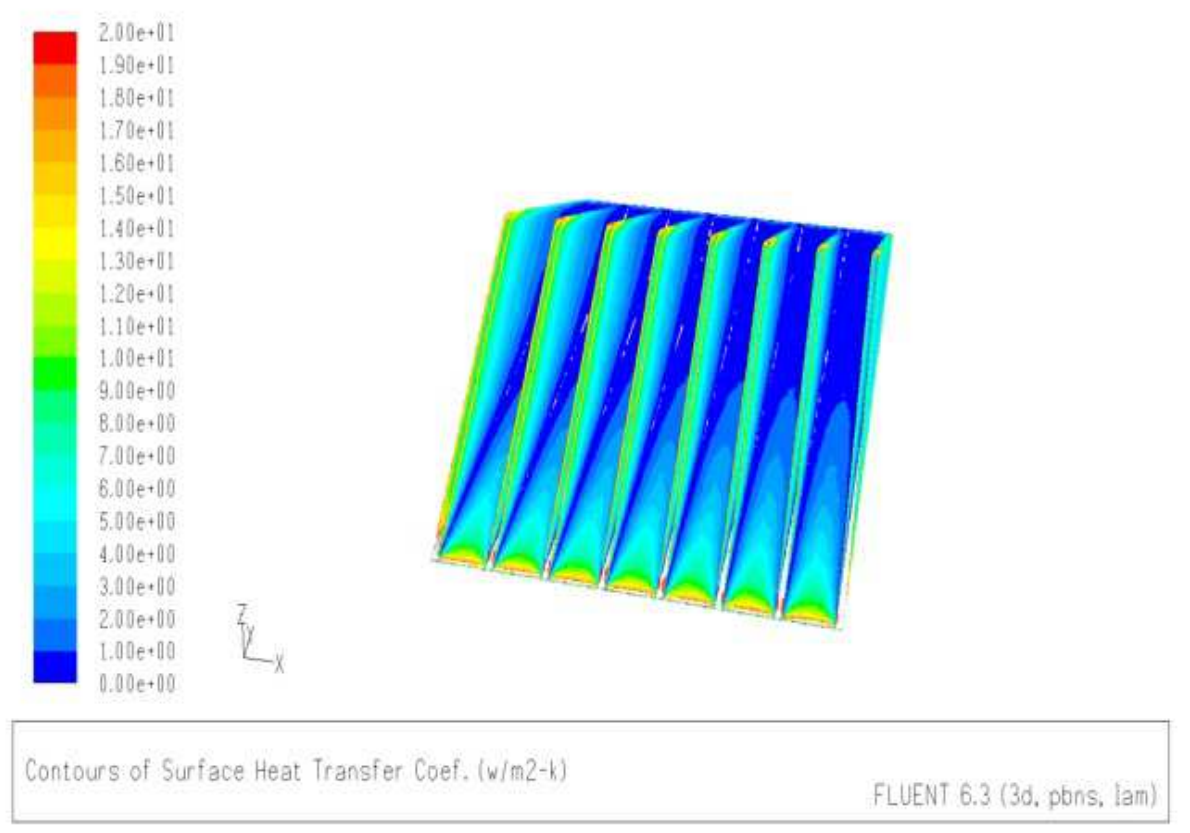

Figure 12. Contour of free convection heat transfer coefficient for 8-fin heat sink.

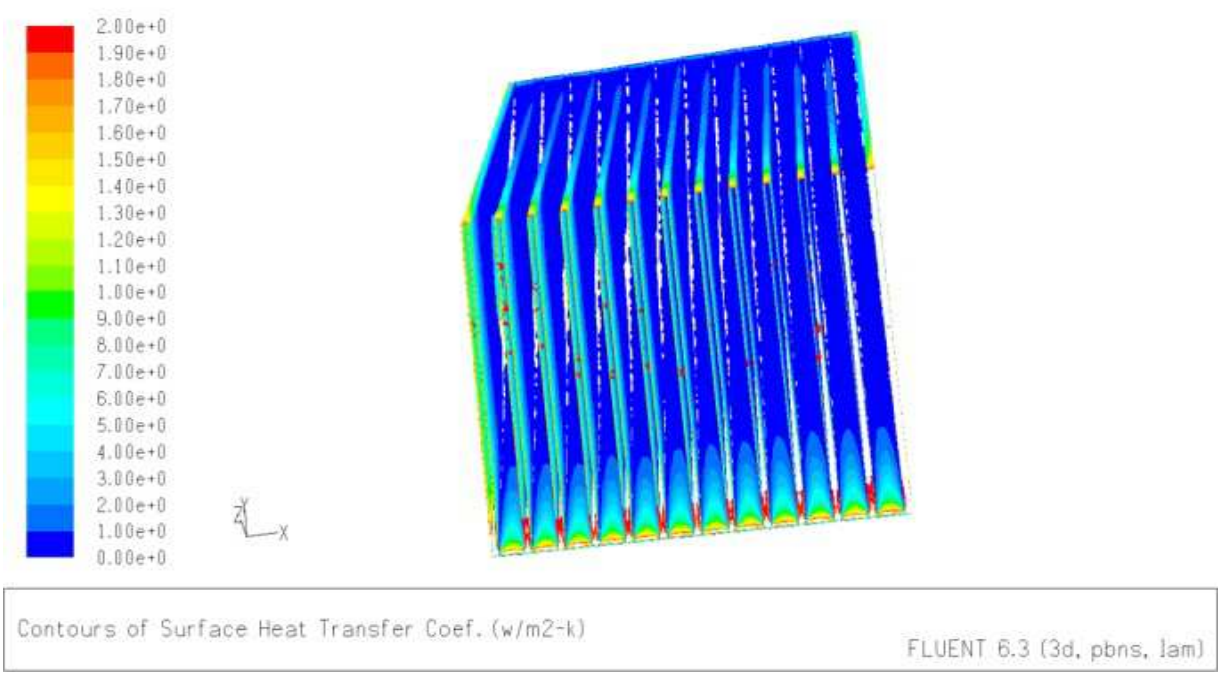

Figure 13. Contour of free convection heat transfer coefficient for 13-fin heat sink.

As mentioned before, if the space between fins is selected appropriately, there would be no interference of boundary layer on surfaces. Figure 10, 11, 12 and 13 show heat boundary layer and interference of boundary layer.

Figure 14 shows the influence of the number of fins in studied heat sink on heat transfer coefficient and heat resistance. As the number of fins increases, free convection heat transfer coefficient decreases, because incoming cool air rate in spaces between fins decreases and the air gets heated earlier. On the other hands, if the number of fins is less than 7 , heat resistance decreases as the number of fins increases, because the effect of increasing heat transfer surface is more than the effect of decreasing heat transfer coefficient. If the number of fins is more than 7 , heat resistance increases as the number of fins increases.

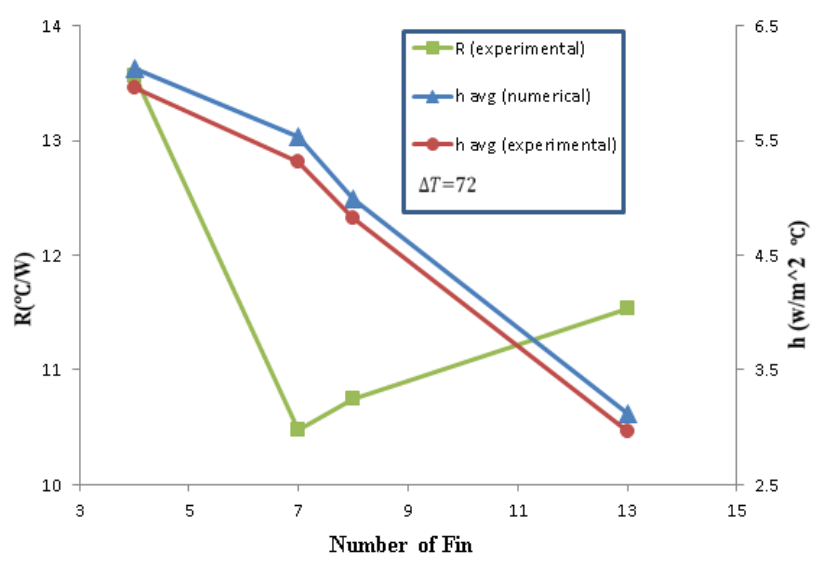

Figure 14. Effects of the number of fins on heat resistance and heat transfer coefficient. 
In order to investigate the influence of space changes between fins on heat resistance, the diagram for changes of heat resistance ratio is provided for temperature differences of 100 and $72{ }^{\circ} \mathrm{C}$ based on the space between fins. The diagram is shown in Figures 15 and 16.

As can be observed, heat resistance decreases as the space between fins increases until the space reaches to the optimum distance. After this point, the value of heat resistance increases with increasing of the distance between fins.

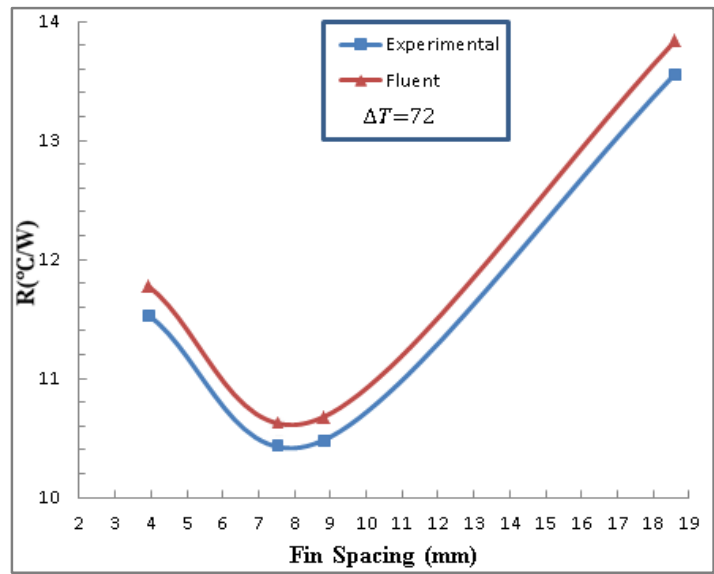

Figure 15. Diagram for heat resistance changes relative to the changes of space between fins for temperature difference of $72{ }^{\circ} \mathrm{C}$.

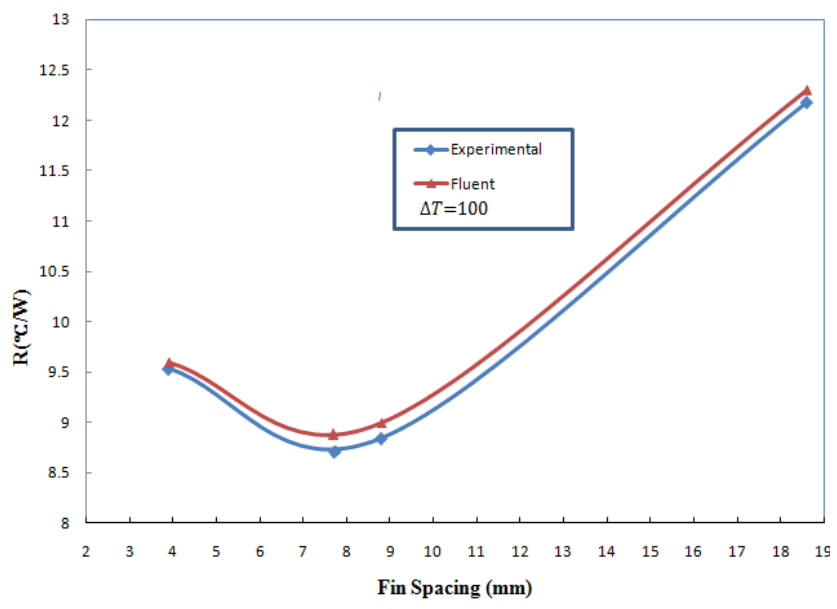

Figure 16. Diagram for heat resistance changes relative to the changes of space between fins for temperature difference of $100^{\circ} \mathrm{C}$.

In figures 17 and 18 , the value for free convection coefficient relative to the space between fins is shown. The value for free convection coefficient increases as the space between fins increases.

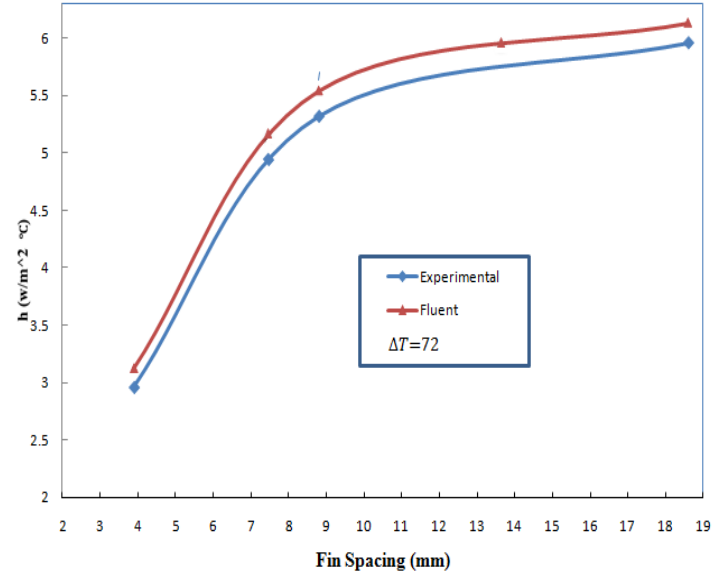

Figure 17. Diagram for free convection coefficient relative to the space between fins for temperature difference of $72^{\circ} \mathrm{C}$

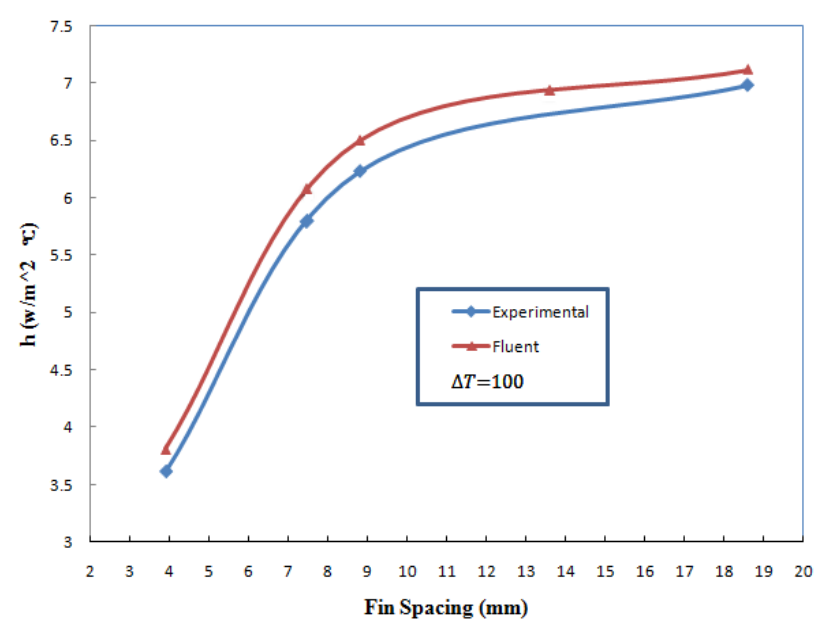

Figure 18. Diagram for free convection coefficient relative to the space between fins for temperature difference of $100^{\circ} \mathrm{C}$.

\section{Conclusions}

According to our paper and the diagrams presented, the optimum distance for a vertical surface possessing triangular fins with above mentioned dimensions is $7 / 9 \mathrm{~mm}$. Moreover it is found that if the number of fins increases or the space between fins decreases, heat transfer rate will increase. The length of the surface should not be considered too high, because turbulence may be observed.

The influence of the space between fins on heat resistance shows that the resistance decreases with increasing of the space until it gets to a minimum point; after this point, heat resistance starts to increase, because incoming cool air rate in spaces between fins decreases and the air gets heated earlier. For future investigation after finding the optimum shape, the effect of row spacing should be studied, and also a correlation should be presented relating the Nusselt number with the Rayleigh number. 


\section{List of Special Symbols}

A Area, $\mathrm{m} 2$

h Heat transfer convection coefficient, w/m2.K

$\mathrm{H} \quad$ Height of the fin, $\mathrm{mm}$

L Length of the fin, $\mathrm{mm}$

$\mathrm{S} \quad$ Space between fins, $\mathrm{mm}$

$\mathrm{n} \quad$ Number of fins

$\mathrm{T}$ Temperature, $\mathrm{K}$

W Width of base surface, $\mathrm{mm}$

\section{References}

[1] Brodowicz, K., "An Analysis of Laminar Free Convection around Isothermal Vertical Plate," International Journal of Heat Mass Transfer, Vol. 11, pp. 201-209, 1968.

[2] J.D. Hellums and S.W. Churchill, "Transient and steady state free and natural convection, Numerical Solutions: Part I. The Isothermal Vertical Plate," American Institute of Chemical Engineers Journal, Vol 8(5), pp. 690-691, 1962.

[3] Pretot, S., Zeghmati, B., and Le Palec, G., "Theoretical and Experimental Study of Natural Convection on a Horizontal Plate," International Journal of Applied Thermal Engineering, Vol. 20, pp. 873-891, 2000.

[4] Comunelo, R., and Güths, S., "Natural Convection at Isothermal Vertical Plate: Neighborhood Influence," 18th International Congress of Mechanical Engineering, Ouro Preto, 2005.

[5] Yüncü H., and Anbar G., "An Experimental Investigation on Performance of Rectangular Fins on a Horizontal Base in Free Convection Heat Transfer," International Journal of Heat and Mass Transfer, Vol. 33, pp. 507-514, 1998.

[6] Saikhedkar N.H, Sukhatme S.P., "Heat transfer from rectangular cross-sectioned vertical fin arrays," in: Proceedings of the sixth national heat and mass transfer conference, HMT,PP. 9-81, 1981.

[7] Guglielmini G., Nannel E., Tanda G., "Natural convection and radiation heat transfer from staggered vertical fin," Heat Mass Transfer 30, 1941-1948, 1987.

[8] Rammohan Rao, Venkateshan S.P., Experimental study of free convection and radiation in horizontal fin arrays, Int. J. Heat Mass Transfer 39 ,779-789,1996.
[9] Rao, V. D., Naidu, S.V., Rao, B.G., and Sharma, K.V., "Heat Transfer from a Horizontal Fin Array by Natural Convection and Radiation a Conjugate Analysis", Int. J. Heat and Mass Transfer. Vol. 49, pp. 3379-3391, (2006).

[10] Naserian, M., Experimental investigation on V type fins. MSc Theses. Mashad Azad University, 2010.

[11] Fahimineya, M Experimental investigation on V type fins. MSc Theses. Mashad Azad University 2010.

[12] Mokheimer EMA.," Performance of annular fins with different profiles subject to variable heat transfer coefficient". Int J Heat Mass Transf,3631-42, 2002.

[13] Gardner KA. Efficiency of extended surface. ASME J Heat Transf,621-31, 1945.

[14] Ullman A, Kalman H.," Efficiency and optimiz dimensions of annular fins of different cross- section shapes". Int J Heat Mass Transf,1105-10,1989.

[15] Karagiozis A; Raithby GD; Hollands KGT "Natural convection heat transfer from arrays of isothermal triangular

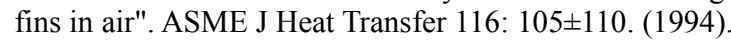

[16] Bert, C.W., "Application of differential transform method to heat conduction in tapered fins". J.Heat Transfer 124, 208 209, 2002.

[17] Moitsheki.,"Steady one-dimensional heat flow in a longitudinal triangular and parabolic fin".3971-3980.2011 Elsevier.

[18] T.H. Ji, S.Y. Kim, J.M. Hyun, Pressure drop and heat transfer correlations for triangular folded fin heat sinks, IEEE Trans. Compon. Packaging Technol. 30 (1).(2007) 3-8.

[19] C. Sun, Y. Bo, H.F. Oztop, Y. Wang, J. Wei, Int. J.Heat Mass Transf.54, 894-909 (2011).

[20] Worachest., Somchai.," Partially wet fin efficiency for the longitudinal fins of rectangular ,triangular, concave parabolic, and convex parabolic profiles".1424-1442.2013.

[21] Gray DD, Giorgini ., 1976, The validity of the boussinesq approximation for liquids and gases, International Journal of Heat and Mass Transfer 19: 545-551.

[22] Patankar SV,1980, "Numerical Heat Transfer and Fluid Flow," McGraw-Hill, New York. 